\title{
Radioprotective action of venom of honey bee Apis mellifera Caucasica
}

\author{
Topchiyeva Shafiga, Babayev Elmar
}

\author{
Institute of Zoology of NAS of Azerbaijan, Baku \\ Adress: AZ1073,Baku, Sabail, Abbasgulu Abbaszadeh,115
}

\begin{abstract}
The paper presents experimental data on the influence of the product of the activity of the honey bee Apis mellifera Caucasica on the life span of experimental animals irradiated with small doses of gamma radiation.

The aim of the studies was to study the radioprotective effect of the pre-introduced zootoxin Apis mellifera Caucasica with a single gamma irradiation of 60Co mice at doses of 1.3, 5, 7, 10 Gy at irradiation dose rates of 1 $\mathrm{Gr} / \mathrm{min}$.

Injection of venom followed by gamma irradiation of 60 Co at a dose of $D=1,3,5$ and $7 G y$ at an irradiation dose rate of $1 \mathrm{~Gy} / \mathrm{min}$ increased the life span of the experimental groups of mice ranging from $45 \%$ to $56 \%$ and from $52 \%$ to $67 \%$, respectively.

An increase in the lifespan of experimental animals exposed to radiation with the preliminary introduction of the venom of the honey bee Apis mellifera Caucasica was revealed.
\end{abstract}

Keywords- honey bee, Apis mellifera Caucasica, venom, radioprotective action.

\section{INTRODUCTION}

The problem of anti-radiation protection is becoming increasingly important in connection with the expansion of the use of ionizing radiation sources in various areas of human activity.

Important tasks of modern pharmacology are the search and development of new effective medicines for the prevention and treatment of various diseases, the study of the mechanisms of their action in animal experiments and the scientific rationale for rational schemes for their application. One of the most severe pathologies, requiring intensive pharmacotherapy and prevention, are radiation injuries arising from acute external radiation exposure [1, 2]

At present, radioprotectors are the most studied and highly effective medical means of radiation protection $[10,15]$. However, their use is limited to the periods of use (exclusively up to radiation exposure), often by a small therapeutic breadth and, as a consequence, enough high toxicity in optimal radioprotective doses. Preparations of cytokines and growth factors are considered as the most promising pharmacological agents for early therapy of radiation pathology [3, 4, 5, 6].

Prevention of adverse effects of irradiation in hazardous doses to humans is achieved through the use of preventive anti-radiation means of radioprotectors.

However, existing radioprotectors do not always meet the requirements for efficacy and tolerability $[7,8]$.

In this regard, both in our country and abroad, the search for new radioprotectors from various classes of chemical compounds, as well as compounds of natural origin, continues.

During the study of the radioprotective effect of anticoagulants, it was found that heparin in the recommended radio-protective dose of $250 \mathrm{U} / \mathrm{kg}$ raises the survival rate of irradiated animals with respect to control by $40-50 \%$.

As the dose decreases by 1 and 2 orders of magnitude, the effectiveness of the drug decreases and when administered at a dose of $2.5 \mathrm{U} / \mathrm{kg}$, the survival gain was only $10 \%$. However, the subsequent reduction in the dose of heparin to $0.25 \mathrm{U} / \mathrm{kg}$ was again accompanied by an increase in its radioprotective effect:

Survival increased to $40-50 \%$, in peripheral blood not only the number of neutrophilic leukocytes, but also the content of cationic proteins in them (according to the lysosomal cation test) significantly increased [9].

No less active is the study of the radioprotective action of zootoxins and preparations of animal origin. In the research of A.S. Koryagina (2006) the radioprotective effect of honey bee venom was studied in detail. For this purpose, rats were injected intraperitoneally with a bee venom at a dose of $0.1 \mu \mathrm{g} / \mathrm{kg}$ for 7 days at a frequency of 1 time per day.

A single total gamma irradiation (60Co) at a dose of $3 \mathrm{~Gy}$ (dose rate of $1 \mathrm{~Gy} / \mathrm{min}$ ) was performed 7 days after the end of injections in the first series of experiments, after 14 days in the second series, 21 days later in the third series and 28 Days in the fourth series of experiments. The radioprotective effects of the bee venom were most pronounced in the first 3 weeks after the end of the injections of zootoxin. During this period, bee venom significantly increased the total number of surviving bone marrow cells. On the 28th day after the injection of 
venom, there was a significant decrease in its antiradiation activity, although it did not disappear completely. The author believes that the radioprotective effect of bee venom is associated with the formation of a nonspecific adaptation reaction [12].

Thus, analyzing the sources of modern literature, it should be noted that domestic and foreign scientists have studied the radioprotective properties of drugs from various pharmacological groups, but currently the search for radioprotectors is actively continuing. All this is due to the relatively low radio-protective efficacy of the substances studied, the toxic properties of radioprotectors and the inability to use them for a long time. However, it is necessary to note the prospects for solving this issue, which may be due to the combined use of radioprotective drugs from various pharmacological groups.

Bee venom Apis mellifera is a complex mixture of enzymes and polypeptides with low molecular weight, including enzymes phospholipase A2, hyaluronidase, phosphomonoesterase, acid esterase, D-glucosidase, lysophospholipase, A-galactosidase, $\alpha$-acetylaminodeoxy glucosidase and arylamidase

It has been revealed that the effect of bee venom on the body shows a decrease in the protein content in the blood serum, which is due to the effect of poison on vascular permeability.

The lethal dose of bee venom for humans is $1.4 \mathrm{mg}$ per 1 $\mathrm{kg}$ of body weight. The lethal outcome comes most often from the paralysis of the respiratory center $[13,14]$.

Because of anticoagulant and anti-inflammatory properties, bee venom is mainly used to treat many inflammatory diseases such as arthritis, bursitis, herpes zoster, joint disease and rheumatoid arthritis Lyme disease, multiple sclerosis and osteoarthritis [16, 17, 18, 19, 20, 21, 22],

Proceeding from a few studies on the effect of bee venom on the life expectancy of experimental animals exposed to radiation a number of issues remain unexplored and is of great scientific and practical interest.

Analyzing the literature data on the degree of study of the venom of honey bees, the aim of the studies was to study the radioprotective effect of the pre-introduced zootoxin Apis mellifera Caucasica with a single gamma irradiation of 60Co mice at doses of 1.3, 5, 7, $10 \mathrm{~Gy}$ at irradiation dose rates of $1 \mathrm{Gr} / \mathrm{min}$.

\section{MATERIAL AND METHODS}

The material of the study was ecologically pure whole poison collected from bees from apiaries, located on ecologically clean territory of Azerbaijan and venom irradiated with small doses of gamma radiation. After taking, venom was stored in a desiccator over a couple of calcium chloride. Water solutions of venom were prepared immediately before the experiment. The choice of doses that cause the development of the adaptation reaction of stable activation is due to the corresponding literary data (Koryagin, Erofeeva, 2004). For mice, these doses are 8-10 mg / $\mathrm{kg}$ of bee venom. In studies of A.Koryagin (2006), when studying the radioprotective effect of honey bee venom in experiments on rats, bee venom was injected at a dose of $0.1 \mu \mathrm{g} / \mathrm{kg}$ [11].

Proceeding from the above, the bee venom dissolved in physiological solution in a dose of $0.1 \mu \mathrm{g} / \mathrm{kg}, 0.2 \mu \mathrm{g} / \mathrm{kg}$, $0.5 \mu \mathrm{g} / \mathrm{kg}, 1.0 \mu \mathrm{g} / \mathrm{kg}$ and $2.0 \mu \mathrm{g} / \mathrm{kg}$ was injected to animals of control groups to study the radioprotective action of the bee venom. A single total $\gamma$-irradiation of 60Co mice was carried out in doses of $\mathrm{D}=1$, 2, 3, 5, 7 Gy at irradiation dose rate of $1 \mathrm{~Gy} / \mathrm{min}$. The experiments were carried out in 5 series of experiments in vitro.

\section{THE RESULTS OF THE RESEARCH AND THEIR DISCUSSION}

We have considered the prevention of radiation damage to experimental animals by venom of the honey bee that occurs when external mice are irradiated.

Table.1: The survival of mice with intraperitoneal injection of bee venom followed by a single $\gamma$-irradiation of 60Co

\begin{tabular}{|c|c|c|c|c|c|}
\hline \multirow{3}{*}{ 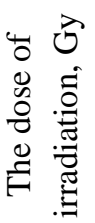 } & \multicolumn{5}{|c|}{ Groups of experimental mice (venom dose in $\mu \mathrm{kg} / \mathrm{kg}$ ) } \\
\hline & control & 0.01 & 0.02 & 0.04 & 0.05 \\
\hline & \multicolumn{5}{|c|}{ Life expectancy in days } \\
\hline 1 & 40 & 45 & 49 & 53 & 58 \\
\hline 3 & 35 & 37 & 42 & 46 & 49 \\
\hline 5 & 23 & 26 & 27 & 31 & 35 \\
\hline 7 & 18 & 21 & 24 & 27 & 28 \\
\hline
\end{tabular}

In order to study the radioprotective effect of the honey bee venom, a control group of mice was irradiated at $\mathrm{D}=$
1, 3, 5, and 7 Gy. Experimental groups of 2-3-month-old white mongrel mice with a total body weight of $18-22$ 
grams were first intraperitoneally injected with bee venom at a dose of $0.01,0.02,0.04$ and $0.05 \mathrm{mg} / \mathrm{kg}$ of body weight, 3 days at a frequency of once a day. Then, the first experimental group of mice was subjected to a single gamma irradiation of $60 \mathrm{Co}$ in a dose of $\mathrm{D}=1 \mathrm{~Gy}$ at a dose rate of $1 \mathrm{~Gy} / \mathrm{min}$ after 3 days, the second experimental group of mice after 3 days subjected to a single gamma irradiation of $60 \mathrm{Co}$ in a dose of D = $3 \mathrm{~Gy}$ at a radiation dose rate of 1 Gy / min. The third experimental group of mice was subjected to a single $\gamma$ irradiation of 60Co in a dose of D $=5 \mathrm{~Gy}$ at a dose rate of 1 Gy / $\min 3$ days after irradiation, and the fourth experimental group of mice, 3 days after irradiation, subjected to single 60Co $\gamma$-irradiation at a dose of $\mathrm{D}=7$ Gy radiation at a dose rate of $1 \mathrm{~Gy} / \mathrm{min}$, the fifth experimental group of mice 3 days later were subjected to single 60Co $\gamma$-irradiation at a dose of $\mathrm{D}=10$ Gy radiation at a dose rate of $1 \mathrm{~Gy} / \mathrm{min}$.

The survival of mice with intraperitoneal injection of bee venom at a dose of 0.01, 0.02, 0.04 and $0.05 \mathrm{mg} / \mathrm{kg}$ of body weight followed by a single $\gamma$-irradiation of 60Co in a dose of $\mathrm{D}=1 \mathrm{~Gy}$ at a dose rate of $1 \mathrm{~Gy} / \mathrm{min}$ is given in Table 1.

The following 5, 6, 7, and 8 groups of experimental mice were injected intramuscularly with bee venom at a dose of $0.1 \mathrm{mg} / \mathrm{kg}$ body weight followed by a single $\gamma$-irradiation of 60Co irradiation at a dose of $\mathrm{D}=1 \mathrm{~Gy}$ at dose rate of 1 Gy / min.

The survival of mice with intramuscular injection of bee venom at a dose of 0.01, 0.02, 0.04, and $0.05 \mathrm{mg} / \mathrm{kg}$ of body weight followed by a single $\gamma$-irradiation of $60 \mathrm{Co}$ at a dose of $1,3,5$ and $7 \mathrm{~Gy}$ at an irradiation dose rate of 1 Gy / min ( table 2).

Table.2: The survival of mice with intramuscular injection of bee venom followed by a single $\gamma$-irradiation of 60Co

\begin{tabular}{|c|c|c|c|c|c|}
\hline \multirow{3}{*}{ 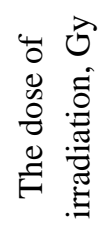 } & \multicolumn{5}{|c|}{ Groups of experimental mice (venom dose in $\mu \mathrm{kg} / \mathrm{kg}$ ) } \\
\hline & control & 0.01 & 0.02 & 0.04 & 0.05 \\
\hline & \multicolumn{5}{|c|}{ Life expectancy in days } \\
\hline 1 & 40 & 47 & 51 & 55 & 61 \\
\hline 3 & 35 & 38 & 44 & 47 & 50 \\
\hline 5 & 23 & 27 & 29 & 33 & 36 \\
\hline 7 & 18 & 23 & 26 & 28 & 30 \\
\hline
\end{tabular}

The following 9, 10,11, 12, and 13 groups of experimental mice were injected intraperitoneally with bee venom at a dose of $0.01,0.02,0.04$ and $0.05 \mathrm{mg} / \mathrm{kg}$ of body weight after a day, subjected to a single gamma irradiation of 60Co at a dose of D $=1,3,5$ and $7 \mathrm{~Gy}$ at an irradiation dose rate of $1 \mathrm{~Gy} / \mathrm{min}$.

Table.3: The survival of mice with intraperitoneal injection of bee venom followed by a single $\gamma$-irradiation of 60Co

\begin{tabular}{|c|c|c|c|c|c|}
\hline \multirow{3}{*}{ 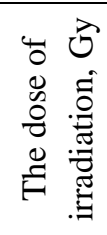 } & \multicolumn{5}{|c|}{ Groups of experimental mice (venom dose in $\mu \mathrm{kg} / \mathrm{kg}$ ) } \\
\hline & control & 0.01 & 0.02 & 0.04 & 0.05 \\
\hline & \multicolumn{5}{|c|}{ Life expectancy in days } \\
\hline 1 & 40 & 42 & 45 & 48 & 52 \\
\hline 3 & 35 & 36 & 39 & 43 & 48 \\
\hline 5 & 23 & 25 & 26 & 29 & 33 \\
\hline 7 & 18 & 19 & 21 & 23 & 25 \\
\hline
\end{tabular}

The survival rate of mice with intraperitoneal injection of bee venom at a dose of 0.01, 0.02, 0.04 and $0.05 \mathrm{mg} / \mathrm{kg}$ of body weight, followed by (after one day) by a single gamma irradiation of $60 \mathrm{Co}$ at a dose of $\mathrm{D}=1,3,5$ and 7 Gy at an irradiation dose rate of $1 \mathrm{~Gy} / \mathrm{Min}$ is shown in table 3.

The following 14, 15, 16, and 17 experimental groups were intramuscularly injected with bee venom at a dose of
$0.01,0.02,0.04$ and $0.05 \mathrm{mg} / \mathrm{kg}$ of body weight after a day, subjected to single $\gamma$-irradiation of 60Co at a dose of $\mathrm{D}=1,3,5$ and $7 \mathrm{~Gy}$ at Dose rate of $1 \mathrm{~Gy} / \mathrm{min}$.

The survival of mice with intramuscular injection of bee venom at a dose of $0.01,0.02,0.04$ and $0.05 \mathrm{mg} / \mathrm{kg}$ of body weight with a single (after a day) $\gamma$-irradiation of $60 \mathrm{Co}$ in a dose of $\mathrm{D}=1,3,5$ and $7 \mathrm{~Gy}$ at a dose rate of 1 Gy / Min are given in Table 4. 
Table.4: The survival of mice with intramuscular injection of bee venom followed by a single $\gamma$-irradiation of 60Co

\begin{tabular}{|c|c|c|c|c|c|}
\hline \multirow{3}{*}{ 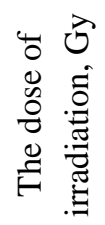 } & \multicolumn{5}{|c|}{ Groups of experimental mice (venom dose in $\mu \mathrm{kg} / \mathrm{kg}$ ) } \\
\hline & control & 0.01 & 0.02 & 0.04 & 0.05 \\
\hline & \multicolumn{5}{|c|}{ Life expectancy in days } \\
\hline 1 & 40 & 43 & 46 & 49 & 54 \\
\hline 3 & 35 & 38 & 40 & 45 & 49 \\
\hline 5 & 23 & 26 & 27 & 30 & 35 \\
\hline 7 & 18 & 20 & 23 & 25 & 27 \\
\hline
\end{tabular}

An increase in the total number of surviving animals was noted in all the groups studied, but the nature of the change in the lifespan of mice differs both from the method of administration and from the time of administration of the poison after gamma irradiation of $60 \mathrm{Co}$.

In experiments on mice with intraperitoneal or intramuscular fractional injection of venom followed by a single $\gamma$-irradiation of $60 \mathrm{Co}$ at a dose of $\mathrm{A}=1,3,5$ and 7 Gy, an increase in the lifespan of experimental groups of mice was noted at an irradiation dose rate of $1 \mathrm{~Gy} / \mathrm{min}$.

The survival rate of the experimental groups of mice, in relation to the control group, ranged from $45 \%$ to $56 \%$ and from $52 \%$ to $67 \%$, respectively.

Survival of the experimental groups of mice, with respect to the control group with a single intraperitoneal or intramuscular injection, increased within the range of $30 \%$ to $39 \%$ and $35 \%$ to $50 \%$, respectively, 24 hours after the injection of venom.

We believe that the radioprotective effect of bee venom is associated with the formation of a nonspecific adaptation reaction.

Thus, we detected a radioprotective effect of the honey bee venom, which manifests itself in an increase in the lifespan of experimental animals subjected to $\gamma$-irradiation of 60Co.

For the first time it was revealed that the injection of venom is accompanied by a prolonged radioresistance, reducing the effect of ionizing radiation on the life span of mice under conditions of a single gamma irradiation.

Consecutive introduction of bee venom to radiation exposure and in the early periods after irradiation allows to increase the survival time of experimental animals subjected to irradiation.

Investigation of the radioprotective effect of the course injection of small doses of bee venom under conditions of a single fractionated gamma irradiation makes it possible to broaden the notion of nonspecific radioresistance and suggests the possibility of creating new preparations on the basis of biologically active substances of animal origin that enhance the radioresistance of the organism.
The practical significance of using bee venom in small doses is that they can be considered as a drug of choice in conditions of fractionated and, possibly, chronic exposure to ionizing radiation.

Radioresistance, which develops in the body in response to multiple injections of bee venom, can successfully protect the body from fractionated gamma irradiation.

\section{CONCLUSIONS}

1. The increase in the lifespan of mice differs from the method of injection, and the time of injection of the venom after $\gamma$-irradiation.

2. Intraperitoneal or intramuscular fractional injection of venom followed by a single gamma irradiation of $60 \mathrm{Co}$ at a dose of $\mathrm{D}=1,3,5$ and $7 \mathrm{~Gy}$ at an irradiation dose rate of $1 \mathrm{~Gy} / \mathrm{min}$ increased the life span of the experimental groups of mice ranging from $45 \%$ to $56 \%$ And from $52 \%$ to $67 \%$.

3. At a single (after 24 hours) intraperitoneal or intramuscular injection of the venom, the life span of the experimental groups of mice increased from $30 \%$ to $39 \%$ and from $35 \%$ to $50 \%$, respectively.

\section{REFERENCES}

[1] Vasin M.V. Anti-radiation drugs / M.V. Vasin. M .: GIUV MO RF, 2010. - 180 p.

[2] Zalyalyutdinova L.N. Study of the influence of a new lithium amino acid complex on the postradiation restoration of hematopoies in the experiment / L.N. Zalyalyutdinova, R.Kh. Khafyazyanov, N.E. Bakirov and others // Fundam. Issled. 2005. - No. 8. - P. 34-35.

[3] Vlasenko TN, Nazarov VB, Grebenyuk AN Modern approaches to pharmacological prevention of radiation damage. Pharmacology, 2010, v.11, p.230253

[4] Maliev V. Mechanisms of action for an antiradiation vaccine in reducing the biological impact of high dose and dose-rate, low-linear energy transfer radiation exposure / Maliev V., Popov D., 
Casey R.C., Jones J.A. // Rad. Biol. Radioecol. 2007. - T. 47, № 3. - C.286-291.

[5] Ovoschnikov L.V. Physiological analysis of the action of salamander poison on the blood system of rats in norm and under experimental radiation damage: Abstract. Dis. Cand. Biol. Sciences / L.V. Ovoschnikov. - N. Novgorod: Nizhegor. State. University, 2004. - $21 \mathrm{p}$.

[6] Koryagin A.S. Duration of radioresistance of the blood system Rats, which occurs when multiple doses of several zootoxins are repeated several times. Mater. 3 Intern. Scientific-practical. Conf. Tambov, 2005. - P. 93-96.

[7] Oršolić N. Assessment by survival analysis of the radioprotective properties of propolis and its polyphenolic compounds / N. Oršolić, V. Benković, A. Horvat-Knežević et al. //Biol. Pharm. Bull. 2007. - Vol. 30, № 5. - P. 946-451.

[8] Son D.J., Lee J.W., Lee Y.H., Song H.S., Lee C.K., Hong J.T. Therapeutic application of anti-arthritis, pain-releasing and anti-cancer effects of bee venom and its constituent compounds. Pharmacol Ther. 2007, (2):246-70.

[9] Orslic N. Bee venom in cancer therapy. Cancer Metastasis Rev. 2012;31, (1-2):173-94.

[10] Billingham M. E., Morley J., Hanson J. M., Shipolini R. A., Vernon C. A., "An antiinflammatory peptide from bee venom". Nature 245: 163-164, 1973

[11] Caldwell J. R. "Venoms, copper and zinc in the treatment of arthritis Rheum". Rheumatic diseases clinics of North America 25: 919-928, 1999.

[12] Eiseman J.L., Bredow J., Alvares A.P. "Effect of honeybee (Apis mellifera) venom on the course of adjuvant-induced arthritis and depression of drug metabolism in the rat". Biochem. Pharm.; 31: 11391146, 1982 (by Schmidt and Buchmann."In. The Hive and the Honey Bee, Edited by Joe M. Graham, Dadant and Sons, Hamilton, Illinois, 1999").

[13] Somerfield S.D., Brandwein S. " Bee venom and adjuvant Arthritis". J. of Rheumatology 15 (12): 1878, 1988.

[14] Manap M.N., Hashim O.H., Yusoff K.M. "Malaysian Bee Venom Abrogates Carrageenan Induced Inflammation in Rats". J. of ApiProduct and ApiMedical Science 3 (2): 75 - 80, 2011.

[15] Castro H.J., Mendez-Lnocenio J.I., Omidvar B., Omidvar J., Santilli J. et all. "A phase I study of the safety of honeybee venom extract as a possible treatment for patients with progressive forms of multiple sclerosis". Allergy and Asthma Proceedings. 26(6): 470-476, 2005.
[16] Kwon Y.B., Kim H.W., Ham T.W., Yoon S.Y. et all. "The anti-inflammatory effect of bee venom stimulation in a mouse air pouch model is mediated by adrenal medullary activity". J. of Neuroendocrinology 15: 93-96, 2003.

[17] Lee W.R., Pak S.C., Park K.K. The Protective Effect of Bee Venom on Fibrosis Causing Inflammatory Diseases Woo-Ram Lee 1, Toxins 2015, 7, 4758-4772;

[18] Krylov V.N., Nikolaev I.N. Effect of bee venom on animal behavior. Apitherapy today: Mater. 11 Int. Scientific-practical. Conf. On apitherapy (July 5-6, 2000). Ufa, 2000, pp. 223-225

[19] Chebyshev N.V., Valtseva I.A., Krylov V.N., Kudryavtsev S.V. Poisonous animals of land and sea. Tutorial. Moscow: MMA them. And M.Sechenova, 1997, $60 \mathrm{p}$

[20] Münstedt K., Bogdanov S. Bee products and their potential use in modern medicine, Journal of Api Product and Api Medical Science 1, 2009, - p. 5763.

[21] http://nuclphys.sinp.msu.ru/cosmrad/cosmrad1.htm

[22] Lukashin B.P. Heparin and radio resistance St. Petersburg: Foliant, 2007. - 128 p. 